\title{
EDUCAÇÃO E MEIO AMBIENTE: REVISÃO DA LITERATURE
}

\section{ARTIGO DE REVISÃO}

SÁ, Gilmara Benicio de ${ }^{1}$

SILVA, Rondinelli de Carvalho ${ }^{2}$

DANOWSKI, Huber Danúbio Correia ${ }^{3}$

BEUTTENMÜLLER, Zailton Frederico ${ }^{4}$

ALVES, José Jakson Amancio ${ }^{5}$

SÁ, Gilmara Benicio de. Et al. Educação e meio ambiente: Revisão da literatura. Revista Científica Multidisciplinar Núcleo do Conhecimento. Ano 05, Ed. 06, Vol. 05, pp. 40-47. Junho de 2020. ISSN: 2448-0959, Link de acesso: https://www.nucleodoconhecimento.com.br/educacao/meio-ambiente

1 Mestrado em Ciências da Educação, Especialização em Educação Infantil e Licenciada em Pedagogia.

2 Mestrado em andamento em Mestrado em Ciências da Educação. Especialização em História Do Brasil. Graduação em História.

${ }^{3}$ Mestrado em Ciências da educação, Especialização em História do Brasil e Licenciado em História e Pedagogia.

${ }^{4}$ Mestrado em Ciências da educação, Especialização em Gestão Pública e Bacharel em Biblioteconomia.

5 Doutorado em Recursos Naturais. Mestrado em Meteorologia [C. Grande]. Especialização em Especialização em Geografia do Nordeste. Graduação em Licenciatura Plena em Geografia. 


\section{RESUMO}

O presente artigo analisa, mediante uma revisão da literatura, a construção de processos identitários no âmbito escolar e permite a contextualização socioambiental de crianças e jovens egressos na educação básica e a sua inserção nas suas dimensões históricas, biológicas, sociais e subjetivas ao articular conceitos e pressupostos que tragam à tona noções de preservação/conservação do meio ambiente a partir do estabelecimento de relações entre o mundo sociocultural e natural de crianças em idade escolar articulados na propositura de estratégias didático-pedagógicas que venham a compreender definições de meio ambiente, os seus componentes biológicos, geográficos, sociais, subjetivos e históricos com o intuito de aplicar tais fundamentos e práticas no contexto das instituições públicas e privadas de ensino e objetivando fornecer material de pesquisa para teóricos e estudiosos da matéria. Metodologicamente, a pesquisa valeu-se de leituras de livros, revistas, artigos científicos, jornais científicos, além de buscar suporte em fontes eletrônicas (internet) para conferir embasamento à análise ora proposta. Como resultado desta revisão literária, espera-se conferir suporte para pesquisadores das temáticas das ciências humanas e do meio ambiente em relação à necessidade de preservação do meio ambiente como forma de oportunizar a reflexão no sentido de fomentar o debate acerca das formas de disseminação de novas condutas educativas em relação aos biomas por parte dos sujeitos componentes da sociedade e da escola.

Palavras-chave: Educação, Meio Ambiente, processos identitários, preservação.

\section{INTRODUÇÃO}

A preservação do meio ambiente depende da preocupação da sociedade de um modo geral para assegurar o acesso à informação por parte de profissionais em educação, educandos e seus familiares em torno da temática abordada, uma vez que o referido assunto deve permear os tecidos reflexivos de todos os integrantes da comunidade escolar, estudiosos e acadêmicos em educação como forma de minimizar os efeitos negativos da não-abertura de espaços dialógicos, com a intenção de trabalhar projetos e planos de ação, experiências vivenciadas e projetos concretos para permitir 
que a sociedade e a escola reflitam sobre o assunto em pauta, oportunizando, dessa forma, o surgimento de uma consciência cidadã por parte dos indivíduos que compõem a comunidade escolar para que estes se inteirem das suas reais necessidades em seu contexto social.

Diante do exposto, a pesquisa defende a importância do debate sobre a criação de uma consciência ambiental docente, discente e coletiva. Percebe-se a falta de informação em torno da conservação/preservação do meio ambiente, e, desse modo, nota-se que o planeta Terra carece de cuidados. Destaca-se, ainda, que mesmo sendo debatidos programas e propostas que tenham em mira a construção de uma nação educadora em meio ambiente, questiona-se se as instituições escolares públicas e privadas de ensino acerca de como têm trabalhado as questões referentes aos impactos ambientais causados pelas ações humanas ao meio ambiente, à coleta seletiva de lixo, ao descarte adequado de material hospitalar e lixo comum, bem como à elevação da autoestima de catadores de lixo a partir da acessibilidade à condições dignas de trabalho, renda e sustentabilidade em nossa sociedade.

Ancorado nesses pressupostos, este estudo propõe uma revisão bibliográfica com o intuito de selecionar trabalhos que tratem de questões ambientais, elencando, para tanto, possíveis soluções para problemas visualizados a partir das leituras, dos estudos e das tomadas de notas e, dessa forma, serão pontuados os posicionamentos com vistas à encaminhamentos futuros.

\section{FUNDAMENTAÇÃO TEÓRICA}

O tema Educação Ambiental deve, antes de tudo, compreender suas diversas concepções. A Educação ambiental é concebida de acordo com a Política Nacional de Educação Ambiental - Lei № 9.795/1999, em seu Art. 1ํㅜ como:

Originada dos processos por meio dos quais o indivíduo e a coletividade constroem valores sociais, conhecimentos, habilidades, atitudes e competências voltadas para a conservação do meio ambiente, bem de 
uso comum do povo, essencial à sadia qualidade de vida e sua sustentabilidade.

O caráter da educação ambiental enquanto 'atividade intencional' é ratificado enquanto prática social capaz de "imprimir ao desenvolvimento individual um caráter social em sua relação com a natureza e com os outros seres humanos, visando potencializar essa atividade humana com a finalidade de torná-la plena de prática social e de ética ambiental" (BRASIL, 2008). Outras convenções e ratificações, como, por exemplo, a Conferência Sub-regional de Educação Ambiental para a Educação Secundária (Chosica), realizada no Peru, em 1976, evidencia que a educação ambiental vem a ser uma ação educativa perene que tem origem na reflexão acerca do contexto global dos indivíduos e coerentes com os tipos de relações que os mesmos promovem:

Estabelecem entre si e com a natureza, dos problemas derivados de ditas relações e suas causas profundas. Ela desenvolve, mediante relações que estabelecem dirigido a transformação superadora dessa realidade, tanto em seus aspectos naturais como sociais, desenvolvendo no educando as habilidades e atitudes necessárias para dita transformação.

Já a Conferência Intergovernamental de Tbilisi (1977) previu que a educação para o meio ambiente pode ser concebida como:

(...) um processo de reconhecimento de valores e clarificações de conceitos, objetivando o desenvolvimento das habilidades e modificando as atitudes em relação ao meio, para entender e apreciar as interrelações entre os seres humanos, suas culturas e seus meios biofísicos. A educação ambiental também está relacionada com a prática das tomadas de decisões e a ética que conduzem para a melhora da qualidade de vida. 
Outras vertentes configuram a educação ambiental enquanto luta política e que deve ser entendida como disputa de posições e proposições acerca dos rumos tomados pela sociedade contemporânea, contemplando, dessa forma, as desterritorializações e os territórios, demonstrando que apenas por meio dos conhecimentos técnicoscientíficos e dos saberes do povo os cidadãos podem galgar os primeiros passos para a sustentabilidade e para a participação social, condizente, portanto, com os princípios de igualdade e fraternidade inerentes ao processo de construção da democracia em um Estado de direito, assertiva essa que é corroborada por Loureiro (2004) ao se referir à dinâmica da educação ambiental enquanto parte integrante da própria educação. Segundo assevera o autor a:

Educação ambiental é uma perspectiva que se inscreve e se dinamiza na própria educação, formada nas relações estabelecidas entre as múltiplas tendências pedagógicas e do ambientalismo, que têm no "ambiente" e na "natureza" categorias centrais e identitárias. Neste posicionamento, a adjetivação "ambiental" se justifica tão somente à medida que serve para destacar dimensões "esquecidas" historicamente pelo fazer educativo, no que se refere ao entendimento da vida e da natureza, e para revelar ou denunciar as dicotomias da modernidade capitalista e do paradigma analítico-linear, não-dialético, que separa: atividade econômica, ou outra, da totalidade social; sociedade e natureza; mente e corpo; matéria e espírito, razão e emoção etc (LOUREIRO, 2004, p. 66).

Para Marconi e Lakatos (2003, p. 15), no que tange à alça metodológica, pode-se verificar que:

A pesquisa pode ser considerada um procedimento formal com método de pensamento reflexivo que requer um tratamento cientifico e se constitui no caminho para se conhecer a realidade ou para descobrir a verdade parciais. Significa muito mais do que apenas procurar a verdade mas descobrir respostas para perguntas ou soluções para os problemas levantados através do emprego de métodos científicos. 
Segundo Minayo (1993, p. 23) é considerada como

Atividade básica das ciências na sua indagação e descoberta da realidade. É uma atitude e uma prática teórica de constante busca que define um processo intrinsecamente inacabado e permanente. É uma atividade de aproximação sucessiva da realidade que nunca se esgota, fazendo uma combinação particular entre teoria e dados.

A efetivação de ações práticas que visam desenvolver a conscientização na tomada de decisões adequadas ao desenvolvimento da Educação ambiental se faz necessária em caráter de urgência, visando proteger o meio ambiente das agressões diárias causadas pelo uso nada sustentável dos recursos naturais, pelo alto consumo desenfreado, pela poluição do meio ambiente, dentre outras atitudes cotidianas da população. Há outros alertas a serem considerados no que se refere à proposição de atividades que buscam sensibilizar essas mudanças de atitudes, tangentes, portanto, à uma:

[...] conscientização "ambientalmente correta" para manter o local de privilégio, onde são desenvolvidas as práticas, conservado para futuras incursões, assim como um discurso de sensibilização sustentado pela necessidade de conservação do meio ambiente. Os estudos do meio caminham nesse mesmo sentido, na maioria das vezes restringindo-se a atividades de sensibilização, que primam pela conservação de uma natureza distante, bela e frágil (RODRIGUES; GONÇALVES JUNIOR, 2009, p. 989).

De acordo com os autores, faz-se necessário a realização de ações ambientais educativas, porém, tendo-se o cuidado de não transmitir uma percepção contrária, isto é, de um meio ambiente distante de sua realidade, sem trazer à tona questões sérias do dia a dia e do próprio corpo como parte importante nesse processo. Isso desencadeia um processo de fragmentação que, na verdade, afasta os indivíduos da compreensão real de que o meio ambiente é todo o espaço onde o ser humano 
desenvolve suas atividades mais simples e complexas da sua vida. Com relação ao uso próprio corpo humano para perceber o ambiente no qual se vive, podemos considerar a importância do uso dos sentidos nesse processo, como afirma Tuan (2012, p. 4):

[...] tanto a resposta dos sentidos aos estímulos externos, como a atividade proposital, na qual certos fenômenos são claramente registrados, enquanto outros retrocedem para a sombra ou são bloqueados. Muito do que percebemos tem valor para nós, para a sobrevivência biológica, e para propiciar algumas satisfações que estão enraizadas na cultura.

Ao se proferir na utilização dos sentidos do corpo humano para a percepção das questões ambientas nos deparamos com a utilização da visão, audição, tato, olfato e paladar para identificar situações de perigos nesse processo de interação com o mundo externo. Cabe, então, ao espaço educativo, promover tais interações em torno dessa questão, dando a questão socioambiental sua devida importância, como preconiza a BNCC:

Ao eleger Educação Ambiental como Tema Especial, almeja-se articular direitos e objetivos de aprendizagem em torno das questões socioambientais, de tal forma que os currículos escolares sejam capazes de debater a continuidade da vida de todas as espécies, inclusive a humana, no planeta terra. Isto exige repensar a desigualdade na distribuição de bens materiais e culturais, bem como a sua produção não sustentável pelo uso predatório dos recursos naturais e pelo consumo desenfreado (MEC, CONSED, UNDIME, 2016, p. 5).

O estudo da Educação ambiental nas escolas evidencia a importância da atuação desse espaço na busca pela formação e incentivo à uma concepção de vida mais ecológica. Esse pensamento que ultrapassa os cuidados individuais promove atitudes coletivas pela preservação de todas as espécies vivas no planeta e, ainda, corrobora 
com a identificação de problemas reais na busca por amenizar os danos causados há anos.

\section{CONSIDERAÇÕES FINAIS}

O presente artigo analisou teoricamente a Educação e Meio Ambiente a partir de uma revisão da literatura. Ao término desta pesquisa concluiu-se que o apoderamento de uma conduta mais ecológica, mesmo que individualmente, contribui para com a mudança de postura das mais diversas gerações. Os hábitos de consumo necessitam de mudanças. O uso racional da utilização de copos de plástico e garrafas pet (Politereftalato de Etila), enviando à reciclagem as utilizadas e reaproveitando de diversas formas é uma prática que irá ajudar o planeta. A educação ambiental necessita de uma política efetiva para a sua implementação. Na segunda década do século XXI 90\% dos detritos encontrados nos oceanos são compostos por plástico e desses, aproximadamente, $30 \%$ correspondem às sacolas de supermercado.

Outra atitude de conscientização é a de não desperdiçar alimentos devido a desigualdade social existente no Brasil. A maior parte do lixo produzido no planeta Terra é o orgânico. $O$ estado Brasileiro necessita promover políticas eficientes nas escolas, sejam elas públicas ou privadas, no que compete a educação do meio ambiente. Deve-se adotar ações que priorizem a preservação do planeta, pois os recursos naturais são fontes esgotáveis e o "jogar fora" está acarretando uma crise no meio ambiente. A preocupação individual e coletiva para a questão ambiental necessita do acesso à informação por meio de uma linguagem adequada para que se desenvolva uma consciência efetiva e crítica, suscitando o enfrentamento das questões ambientais e sociais em nosso período vigente.

A educação ambiental toma forma em um contexto complexo, e, dessa forma, para se chegar às mudanças de hábitos almejadas é necessário um trabalho amplo e contínuo no espaço escolar e a temática deve, inclusive, ser uma pauta política. 


\section{REFERÊNCIAS}

BRASIL. Diretrizes Curriculares Nacionais para a Educação Ambiental, Art. $2^{\circ}$. Brasília: MEC/SEF, 2008.

DIEZ, C. L. F. Pesquisa Quantitativa x Pesquisa Qualitativa. In: Orientações para elaboração de projetos e monografias. 3a . ed. rev. atual. Petrópolis: Vozes, 2013.

GIL, A. C. Que é pesquisa bibliográfica? In: Como elaborar projetos de pesquisa. 4ํㅡㄹ ed. São Paulo: Editora Atlas, 2008.

. Como delinear uma pesquisa bibliográfica. In: Como elaborar projetos de pesquisa. 4⿳亠丷a ed. São Paulo: Editora Atlas, 2008.

LOUREIRO, C. F. B. Educação Ambiental Transformadora. In: Identidades da Educação Ambiental Brasileira. Brasília: Ministério do Meio Ambiente, 2004.

MARCONI, M. de. A.; LAKATOS, E. V. Fundamentos de metodologia científica. $5^{a}$ ed. São Paulo: Atlas, 2003.

MEC. CONSED. UNDIME. Base Nacional Comum Curricular, segunda versão revista. $2016 . \quad$ Disponível em: http://basenacionalcomum.mec.gov.br/documentos/bncc2versao.revista.pdf. Acesso em: 15 dez. 2016.

MINAYO, M. C. S. O desafio do conhecimento: pesquisa qualitativa em saúde. São Paulo, Huicitec, 1993.

RODRIGUES, C.; GONÇALVES JUNIOR, L. Ecomotricidade: sinergia entre educação ambiental, motricidade humana e pedagogia dialógica. Revista Motriz, v. 15, n. 4, p. 987-995, out./dez. 2009.

TUAN, Y. F. Topofilia: um estudo da percepção, atitudes e valores do meio ambiente. São Paulo: Eduel, 2012. 
Enviado: Abril, 2020.

Aprovado: Junho, 2020. 